\title{
Environmental Effects on the Photophysics of Organic-Inorganic Halide Perovskites
}

\author{
Juan F. Galisteo-López,* M. Anaya, M. E. Calvo, and H. Míguez* \\ Instituto de Ciencia de Materiales de Sevilla, Consejo Superior de Investigaciones Científicas (CSIC), Universidad de Sevilla, \\ C/Américo Vespucio 49, 41092 Sevilla, Spain
}

\section{Supporting Information}

ABSTRACT: The photophysical properties of films of organicinorganic lead halide perovskites under different ambient conditions are herein reported. We demonstrate that their luminescent properties are determined by the interplay between photoinduced activation and darkening processes, which strongly depend on the atmosphere surrounding the samples. We have isolated oxygen and moisture as the key elements in each process, activation and darkening, both of which involve the interaction with photogenerated carriers. These findings show that environmental factors play a key role in the performance of lead halide perovskites as efficient luminescent materials.

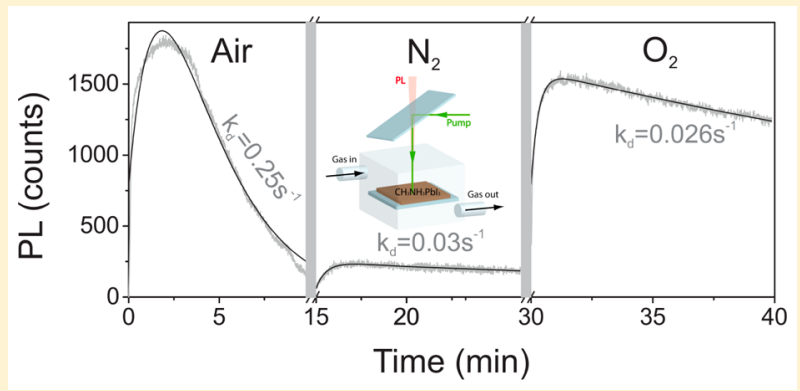

nonradiative de-excitation pathways for photogenerated carriers, ${ }^{15-17}$ its combination with darkening on similar time scales has not been reported. In order to gain understanding into the origin of these two processes, we consider the effect of the atmosphere by placing the samples under controlled ambient conditions. We find that while trap state filling by photogenerated carriers is likely responsible for the activation of the perovskite PL, the role of the surrounding atmosphere is crucial, pointing to oxygen being determinant. On the other hand, the photodarkening process is linked with the presence of water in the environment, but contrary to previous reports, ${ }^{5,7}$ this photoinduced process is partially reversible and does not present signs of material degradation, such as changes in absorption or material color. An analytical model allows us to quantify the effect of the different atmospheres on the activation and deactivation phenomena responsible for the observed photoemission dynamics. Our findings constitute a step forward toward the understanding of the emissive properties of lead halide perovskites needed to establish clear guidelines to design future efficient light-emitting devices.

Thin (ca. $300 \mathrm{~nm}$ ) perovskite films were deposited on low fluorescence glasses by spin coating (see the Experimental Section). The preparation procedure is based on the antisolvent engineering ${ }^{18}$ in which the perovskite precursors are deposited by spin-coating. After $6 \mathrm{~s}$, chlorobenzene is added in order to induce crystallization, giving rise to a narrow crystal size distribution around an average controlled value of hundreds of nanometers (estimated to be around $300 \mathrm{~nm}$ in our particular case) as our goal was to minimize the potential effect of grain

Received: April 15, 2015

Accepted: May 27, 2015

Published: May 27, 2015 
boundaries. Nevertheless, the results presented throughout the Letter are not dependent on the sample preparation as similar samples fabricated according to a different procedure ${ }^{19}$ showed similar photophysical properties. Scanning electron microscopy (SEM) and X-ray diffraction (XRD) characterization results are provided as Supporting Information (Figures S1 and S2). Absorption measurements show a sharp band edge at $750 \mathrm{~nm}$, accompanied by a PL peak at $775 \mathrm{~nm}$ with a full width at halfmaximum (fwhm) of $45 \mathrm{~nm}$ under optical excitation with monochromatic laser light (see Figure 1). The evolution of the

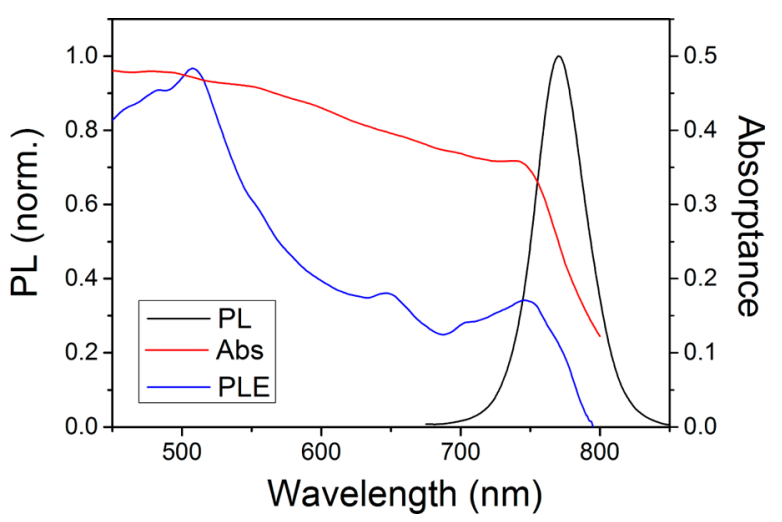

Figure 1. Normalized PL and PLE (black and blue, respectively) and absorptance (red line) spectra from thin perovskite films.

PL maximum was monitored as the excitation wavelength was scanned throughout the visible. The spectral trend of this photoluminescence excitation (PLE) curve was found to be different from that of the absorbance with two clear maxima at 510 and $750 \mathrm{~nm}$. These spectral positions coincide with the transition between a dual valence band and a conduction band already reported. ${ }^{20}$ The marked difference between absorbance and PLE evidences that carriers generated by photons with large energy have a higher contribution to the PL than carries produced at low energy.

Beyond its dependence with the excitation wavelength, the PL peak presents a slow (in the range of minutes under the present optical pump conditions) dynamics with an initial photoactivation stage followed by a photodarkening one. As a matter of fact, both processes are likely taking place simultaneously, the latter becoming the dominant one after a time $t_{c}$. This feature becomes evident when one plots the PL maximum $(\lambda=775 \mathrm{~nm})$ (see Figure $2 \mathrm{a}$ ) as a function of illumination time. Simultaneously with the PL measurements, we monitored the absorption at the excitation wavelength (see Figure $2 \mathrm{~b}$ ). Here, it is evident that large changes in PL intensity are accompanied by a nearly constant pump absorption (fluctuations of $\sim 2 \%$ ). This behavior indicates that the variation in the sample emission is due to changes in quantum yield related with the interplay between the efficiency of radiative and nonradiative decay paths of the photogenerated carriers. Further, if we compare PL spectra collected at three different stages of the collection period, it can be appreciated that no changes in the spectral shape take place (see Figure 2c), which indicates that the electron transitions involved in the PL time evolution observed have a nonradiative character.

Both photoactivation and photodarkening processes are strongly dependent on the intensity of the pump beam. Upon increasing the intensity, the PL raises linearly, and both activation and darkening rates increase, as evidenced by the
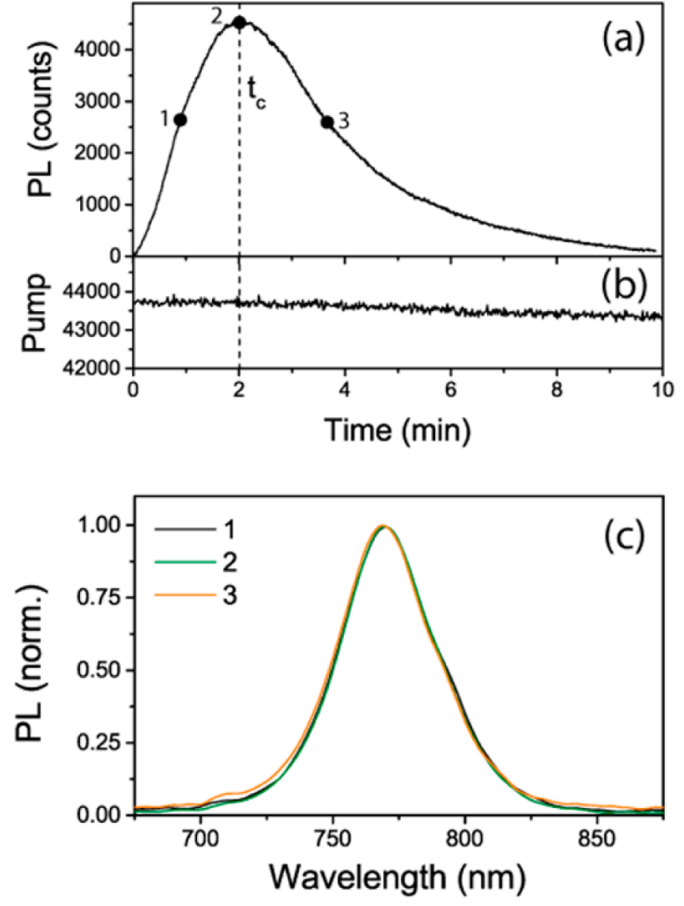

Figure 2. (a) PL maximum $(\lambda=775 \mathrm{~nm})$ as a function of time under excitation with monochromatic light at $\lambda=500 \mathrm{~nm}$. (b) Transmitted pump intensity. (c) Normalized PL spectra at three stages of the time evolution (marked by numbered dots in (a)).

slopes of the slow dynamics of the PL (see Figure 3a). For an excitation intensity above $0.7 \mathrm{~W} / \mathrm{cm}^{2}$, the $\mathrm{PL}$ dynamics reaches a stationary behavior, as evidenced by the evolution of $t_{c}$ (Figure 3b).
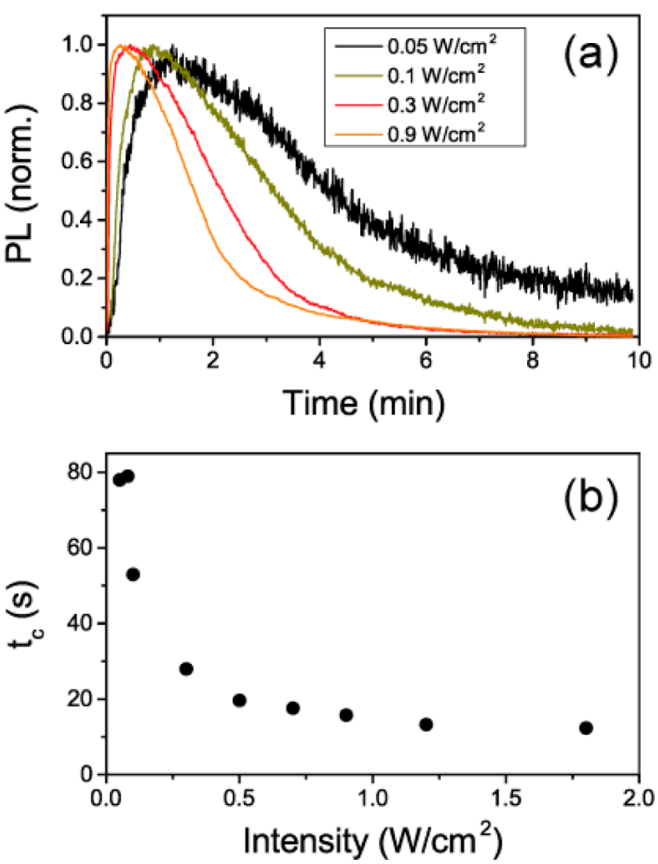

Figure 3. (a) Evolution of the PL maximum $(\lambda=775 \mathrm{~nm})$ as a function of time under excitation with monochromatic light at $\lambda=500$ $\mathrm{nm}$ for different pump intensities. (b) Time elapsed to reach the PL maximum, $t_{\mathcal{c}}$ against excitation intensity. 
Photoactivation emission dynamics have been recently reported in a number of publications. ${ }^{15-17,21}$ While some reports point to the existence of a change in the material morphology upon illumination, ${ }^{16}$ it is not the case in our findings as the reported material modifications are accompanied by strong changes in the PL spectral shape that are not observed here (see Figure $2 \mathrm{~b}$ ). It has also been suggested by Sánchez and co-workers ${ }^{21}$ that slow changes in PL from the perovskite can be due to preferential absorption of light with different polarization by crystal domains with different orientations, something that we tested by using linearly and circularly polarized light and observing no change in the slow dynamics (see Figure S3, Supporting Information). Similar slow (seconds to minutes) dynamics have been observed in the evolution of the photocurrent in perovskite thin films and photovoltaic devices and associated with structural changes, ${ }^{22}$ the appearance of spatial charge near the electrodes as a consequence of ion migration, ${ }^{23}$ and the existence of ferroelectric domains. ${ }^{24}$ In several cases, such slow response has been associated with the hysteresis usually measured in the photocurrent under forward and reverse bias scan of perovskitebased solar cells. While taking place on a similar time scale, we believe that the above mechanisms are not the origin of the presented behavior of the photophysics as our samples are not being exposed to an external bias. The photoactivation is likely related to the filling of subgap trap states, which limit the PL of the perovskite. ${ }^{15}$ The nature of these traps, which can be shallow or deep, will depend on the kind of defect originating it. Recent numerical simulations have predicted defect states at several positions spanning the whole band gap of the perovskite. $^{25,26}$ In our case, independent of the nature of the defect, we have observed that carriers trapped at these states do not affect the spectral shape of the PL of the samples as no lowenergy PL band associated with defect state emission was observed up to $\lambda=950 \mathrm{~nm}$.

Next, we focus on the photodarkening of the perovskite films under prolonged optical pumping. This process can be due to the degradation of the perovskite matrix under illumination, as recently reported in a number of studies. ${ }^{3-6}$ A combination of illumination and high temperature has been demonstrated to degrade similar perovskite films as a consequence of the decomposition of the perovskite matrix that leads to $\mathrm{PbI}_{2}$ crystallization. In our case, such temperature-triggered degradation (which could be caused by local heating by the pump beam) can be ruled out. On the one hand, no physical change associated with the color of the perovskite film was observed after illumination experiments. Further, if $\mathrm{PbI}_{2}$ formed as a subproduct of the degradation, its PL would be observed in the spectra collected at times where the perovskite PL starts to decrease. No emission from crystalline $\mathrm{PbI}_{2}$ (expected at $\lambda=$ $500 \mathrm{~nm}$ ) was observed when pumped with a wavelength of 450 $\mathrm{nm}$. Other evidence of the absence of material degradation comes from the fact that no change in the absorption of the pump is detected throughout the whole transient behavior (see Figure $2 \mathrm{~b}$ ), contrary to reports where a strong modification of the transmittance accompanies perovskite degradation. ${ }^{5,6}$ A worsening of perovskite solar cell performance has been also observed under UV illumination and attributed to the interaction between the perovskite and a $\mathrm{TiO}_{2}$ scaffold. ${ }^{4}$ As we are dealing with the bulk perovskite material irradiated with visible light, our observations must represent a different mechanism.
In order to gain further insight into these two processes, we studied the photophysics of the samples under ambient as well as $\mathrm{N}_{2}$ and $\mathrm{O}_{2}$ atmospheres. Samples were kept in an environment-controlled chamber through which the different gases were passed. The time evolution of the PL was measured by sequentially changing the atmosphere. Between each measurement, the sample was exposed to the corresponding gas flux without any illumination for a period of $5 \mathrm{~min}$ in order to guarantee a complete replacement of the atmosphere. Figure 4 shows the evolution of the PL maximum as we expose the

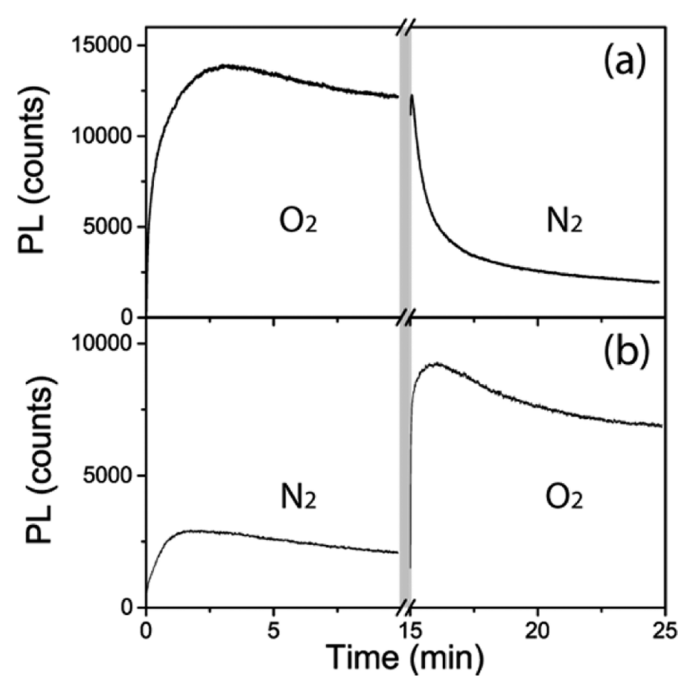

Figure 4. Dynamics of the PL maximum under constant pump conditions for bulk perovskites under different atmospheric conditions. (a) Passing an $\mathrm{O}_{2}$ flux followed by a $\mathrm{N}_{2}$ one. (b) Passing a $\mathrm{N}_{2}$ flux followed by an $\mathrm{O}_{2}$ one. Note that before each measurement with a given gas, the sample is exposed to it for $5 \mathrm{~min}$ (break in the $x$-axis and gray band).

samples to $\mathrm{O}_{2} / \mathrm{N}_{2}$ and $\mathrm{N}_{2} / \mathrm{O}_{2}$ sequential fluxes. From these results, it is evident that the photoactivation of the PL strongly depends on the surrounding atmosphere. In particular, the activation is more effective in the presence of $\mathrm{O}_{2}$ than $\mathrm{N}_{2}$. If the activation process is in fact related with the filling of charge traps, as recently suggested, the present results point to oxygen playing a relevant role in the process. A plausible scenario is that of photoexcited charges being trapped at noncoordinated $\mathrm{Pb}^{2+}$ species lying at the sample surface and at grain boundaries $^{27,28}$ and promoting the passivation of such traps by the formation of lead oxide, as has been recently proposed. ${ }^{28}$ While this mechanism is energetically favorable and would also explain why the activation effect remains for at least the $5 \mathrm{~min}$ period of darkness, its reversibility in the presence of $\mathrm{N}_{2}$ (and over a series of successive cycles) means that further tests will be needed to understand the details of this dynamic process, which demands the presence of light and strongly depends on the atmosphere surrounding the sample.

From the results of Figure 4, it is evident that the strong photodarkening is mainly due to the presence of moisture in the atmosphere surrounding the samples when the sample is illuminated in air. If we study the evolution of the PL under air/ $\mathrm{N}_{2} / \mathrm{O}_{2}$ while optically pumping with a constant intensity $(0.3$ $\mathrm{W} / \mathrm{cm}^{2}$ ), we find that the drop in PL of over $90 \%$ observed in air is reduced to $15-20 \%$ when the sample is placed in $\mathrm{N}_{2}$ or $\mathrm{O}_{2}$ (see Figure 5). Further, from the results in Figure 5, it can be seen that the photodarkening during illumination in air is 


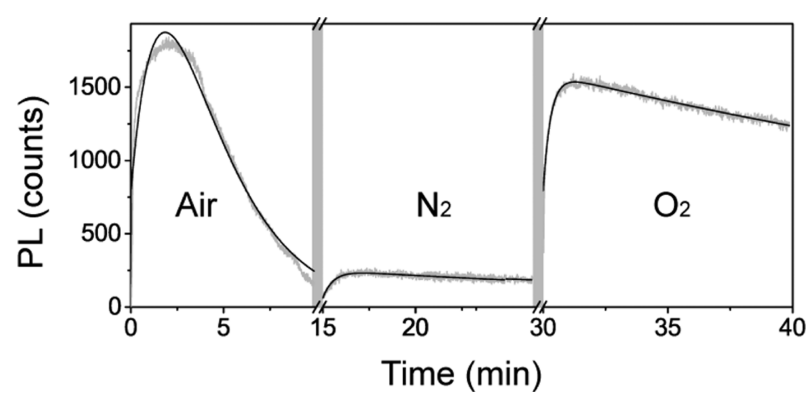

Figure 5. Evolution of the PL maximum with the sample exposed to different atmospheres. Gray (black) curves correspond to experimental data (fits). Note that before each measurement with a given gas, the sample is exposed to it for $5 \mathrm{~min}$ (break in the $x$-axis and gray band).

partially reversible when the sample is placed in $\mathrm{O}_{2}$ at a later time. We also note that such recovery upon changing the atmosphere from air to $\mathrm{O}_{2}$ demands illumination, that is, it is a photoactivated process. The origin of such moisture-related photodarkening is likely related to the formation of hydrated species whose formation has been found to be favored by photoexcited carriers, weakening the hydrogen bonds between organic cations and $\mathrm{PbI}_{6}$ octahedra ${ }^{7,22}$ and promoting the formation of complexes with $\mathrm{H}_{2} \mathrm{O}$ molecules. While previous reports of perovskite hydration have been presented in the context of degradation of the material, our observations correspond to a (partially) reversible process when the sample is illuminated in $\mathrm{O}_{2}$.

The role of the atmosphere on perovskite performance has been recently studied ${ }^{29,30}$ in the context of its effect during the synthesis of the material, where annealing in the presence of moisture has been shown to improve sample performance via two paths, favoring the formation of large crystallites (and hence fewer surface and grain boundary defects) and partial passivation of noncoordinated atoms at the surface by $\mathrm{O}_{2}$ and $\mathrm{H}_{2} \mathrm{O}$ molecules. Here, we have demonstrated that beyond its effect during their fabrication, the atmosphere plays a crucial role in the photophysics of perovskites. While further research will be required to understand the detailed role of $\mathrm{H}_{2} \mathrm{O}$ and $\mathrm{O}_{2}$ on the photoactivated processes, our present results point toward the possibility of atmospheric control as a mechanism to further improve the performance of perovskite materials in different optoelectronic devices. While charge trapping is expected to play a crucial role in the observed mechanisms according to recent reports, ${ }^{15-17}$ our results point to a dynamic process involving an interaction, mediated by photogenerated carriers, with the atmosphere in which moisture should be avoided while $\mathrm{O}_{2}$ is needed for efficient PL. Such control could be combined with postannealing treatments recently proposed as a means to passivate traps associated with uncoordinated $\mathrm{Pb}$ or I atoms at the surface. ${ }^{28,31}$ It is interesting to notice that a similar behavior has been observed in the field of semiconductor nanocrystals, ${ }^{32}$ for which the combined role of carrier trap filling and atmosphere has also been pointed out, although, in that case, moisture was shown to foster PL rather than quench it.

In order to quantify the effect of the atmosphere on the photoinduced processes, we have used a consecutive elementary processes model to fit (see the Supporting Information) the above-reported slow dynamics of the PL in different atmospheres (see Figure 5). In this model, the competition between luminescence activation and deactivation mechanisms is assumed, regardless of their origin. ${ }^{33}$ In this way, the effect on the radiative dynamics of the different environmental conditions employed can be quantified. In the present case, we have obtained activation rates $k_{\mathrm{a}}$ with very similar values in air $\left(1.2 \mathrm{~s}^{-1}\right)$ and $\mathrm{N}_{2}\left(1.8 \mathrm{~s}^{-1}\right)$ but larger ones in $\mathrm{O}_{2}$ $\left(4.6 \mathrm{~s}^{-1}\right)$, evidencing its key role in this process. A more drastic change is observed in the evolution of the darkening rate $k_{\mathrm{d}}$, which drops by an order of magnitude as we change from air $\left(0.255 \mathrm{~s}^{-1}\right)$ to $\mathrm{N}_{2}\left(0.031 \mathrm{~s}^{-1}\right)$ or $\mathrm{O}_{2}\left(0.026 \mathrm{~s}^{-1}\right)$. Within this picture, the activation rate $k_{\mathrm{a}}$ can be identified with the photoinduced passivation of charge traps, while $k_{\mathrm{d}}$ is associated with the creation of hydrated species that quench the PL of the samples, a process that can be largely avoided by removing water from the atmosphere. While the ultimate mechanism responsible for the activation/darkening of the PL will require future work, these results clearly show how the photophysics of $\mathrm{CH}_{3} \mathrm{NH}_{3} \mathrm{PbI}_{3}$ perovskites are strongly influenced by the atmosphere, and changes of up to an order of magnitude in the darkening of its PL can be exerted by just modifying the operation environment of the samples.

We have studied the photophysics of hybrid organicinorganic lead halide perovskite films under different atmospheres. A combination of photoinduced activation and darkening processes has been shown to determine their luminescence. By exposing the perovskite films to different atmospheres while optically pumping them, we have isolated the predominant role of oxygen during the photoactivation and moisture in the photodarkening. While further research will be needed to understand the details of both processes, a reaction between the atmosphere and the sample triggered by photogenerated carriers, involving the formation of oxide and hydrate species, is likely at the core of the observed phenomena. These findings point toward a controlled atmosphere being a key factor in the development of efficient perovskite-based luminescent devices.

\section{EXPERIMENTAL SECTION}

Sample Fabrication. Methylammonium iodide $\left(\mathrm{CH}_{3} \mathrm{NH}_{3} \mathrm{I}\right)$ was prepared by dissolving methylamine (Sigma-Aldrich 534102) in absolute ethanol and reacting with hydroiodic acid (SigmaAldrich 210021) in an ice bath. Then, $12.4 \mathrm{~mL}$ of methylamine and $6 \mathrm{~mL}$ of hydroiodic acid were mixed with $50 \mathrm{~mL}$ of ethanol. The solvent was removed by rotary evaporation, and the obtained white powder was washed with anhydrous diethyl ether. Finally, the product was dried overnight under vacuum at $80{ }^{\circ} \mathrm{C}$. $\mathrm{CH}_{3} \mathrm{NH}_{3} \mathrm{I}$ and $\mathrm{PbCl}_{2}$ (Sigma-Aldrich 268690) were dissolved at a final concentration of $40 \mathrm{wt} \%$ in anhydrous $\mathrm{N}, \mathrm{N}$ dimethylformamide (DMF) (the molar ratio between $\mathrm{CH}_{3} \mathrm{NH}_{3} \mathrm{I}$ and $\mathrm{PbCl}_{2}$ was $3: 1$ ).

$\mathrm{MAPbI}_{3}$ films were grown onto clear white glass substrates (ProScitech) previously cleaned sequentially in ethanol, acetone, 2-propanol, and finally treated oxygen plasma for 300 s. $\mathrm{CH}_{3} \mathrm{NH}_{3} \mathrm{PbI}_{3}$ precursor solution $(100 \mu \mathrm{L})$ was deposited (substrate area $\approx 2 \mathrm{~cm} \times 2 \mathrm{~cm}$ ) by spin-coating at $5000 \mathrm{rpm}$. After $6 \mathrm{~s}$, while the spinning process took place, $200 \mu \mathrm{L}$ of anhydrous chlorobenzene was dropped onto the center of the substrate, as previously reported. The resulting films were then annealed at $100{ }^{\circ} \mathrm{C}$ for $3 \mathrm{~h}$, until a pure $\mathrm{CH}_{3} \mathrm{NH}_{3} \mathrm{PbI}_{3}$ layer was obtained.

Optical Characterization. Total transmittance $(T)$ and total reflectance $(R)$ spectra of the $\mathrm{CH}_{3} \mathrm{NH}_{3} \mathrm{PbI}_{3}$ films were measured using an integrating sphere attached to a UV-vis spectrophotometer (Shimadzu UV-2101 PC). The spectral 
dependence of the absorptance $(A)$ of the $\mathrm{CH}_{3} \mathrm{NH}_{3} \mathrm{PbI}_{3}$ films was determined by making use of the formula $A=1-R-T$.

PLE measurements were performed in a commercial fluorometer (Fluorolog 3 from Horiba). The samples were excited with a spot of $1 \times 1 \mathrm{~cm}^{2}$ with a wavelength variable between 450 and $850 \mathrm{~nm}(\mathrm{fwhm}=5 \mathrm{~nm})$, and detection was carried out at an angle of $\theta=22.5^{\circ}$ at the maximum of PL $(\lambda=$ $775 \mathrm{~nm})$.

PL measurements were carried out by optically pumping the samples with a tunable picosecond laser source (Fianium SC400) delivering low power (sub-mW), 900 ps long pulses with a $1 \mathrm{kHz}$ repetition rate. The pump beam was focused down to a $100 \mu \mathrm{m}$ spot with an achromatic lens $(f=10 \mathrm{~cm})$, which also collected the emission. Spectra were collected at 0.5 $s$ intervals with a fiber-coupled spectrometer (USB2000 from Ocean Optics).

\section{ASSOCIATED CONTENT}

\section{S Supporting Information}

Scanning electron microscopy (SEM) images of the measured samples. XRD data of perovskite films. Polarization-resolved photoluminescence measurements. Description of the consecutive elementary reaction (CER) model used to fit the data. The Supporting Information is available free of charge on the ACS Publications website at DOI: 10.1021/acs.jpclett.5b00785.

\section{AUTHOR INFORMATION}

\section{Corresponding Authors}

*E-mail: juan.galisteo@csic.es (J.F.G.-L.).

*E-mail: h.miguez@csic.es (H.M.).

\section{Notes}

The authors declare no competing financial interest.

\section{ACKNOWLEDGMENTS}

The research leading to these results has received funding from the European Research Council under the European Union's Seventh Framework Programme (FP7/2007-2013)/ERC Grant Agreement $\mathrm{N}^{\circ} 307081$ (POLIGHT) and the Spanish Ministry of Economy and Competitiveness under Grant MAT201454852-R. FESEM characterization was performed at CITIUS, and we are grateful for its support. M.A. is grateful to La Caixa Foundation for its financial support.

\section{REFERENCES}

(1) Green, M. A.; Ho-Baillie, A.; Snaith, H. J. The Emergence of Perovskite Solar Cells. Nature Photonics. 2014, 8, 506-514.

(2) Jeon, N. J.; Noh, J. H.; Yang, W. S.; Kim, Y. C.; Ryu, S.; Seo, J.; Seok, S. I. Compositional Engineering of Perovskite Materials for High-Performance Solar Cells. Nature 2015, 517, 476-480.

(3) Noh, J. H.; Im, S. H.; Heo, J. H.; Mandal, T. N.; Seok, S. I. Chemical Management for Colorful, Efficient, and Stable InorganicOrganic Hybrid Nanostructured Solar Cells. Nano Lett. 2013, 13, 1764-1769.

(4) Leitjens, T.; Eperon, G. E.; Pathak, S.; Abate, A.; Lee, M. M.; Snaith, H. J. Overcoming Ultraviolet Light Instability of Sensitized $\mathrm{TiO}_{2}$ with Meso-Superstructured Organometal Tri-halide Perovskite Solar Cells. Nat. Commun. 2013, 4, 2885-2896.

(5) Niu, G.; Li, W.; Meng, F.; Wang, L.; Dong, H.; Qiu, Y. Study on the Stability of $\mathrm{CH}_{3} \mathrm{NH}_{3} \mathrm{PbI}_{3}$ Films and The Effect of Post Modification by Aluminum Oxide in All Solid State Hybrid Solar Cells. J. Mater. Chem. A 2014, 2, 705-710.

(6) Misra, R. K.; Aharon, S.; Li, B.; Mogilyanski, D.; Visoly-Fisher, I.; Etgar, L.; Katz, E. A. Temperature- and Component-Dependent
Degradation of Perovskite Photovoltaic Materials under Concentrated Sunlight. J. Phys. Chem. Lett. 2015, 6, 326-330.

(7) Christians, J. A.; Miranda Herrera, P. A.; Kamat, P. V. Transformation of the Excited State and Photovoltaic Efficiency of $\mathrm{CH}_{3} \mathrm{NH}_{3} \mathrm{PbI}_{3}$ Perovskite upon Controlled Exposure to Humidified Air. J. Am. Chem. Soc. 2015, 137, 1530-1538.

(8) Boix, P. P.; Agarwala, S.; Koh, T. M.; Mathews, N.; Mhaisalkar, S. G. Perovskite Solar Cells: Beyond Methylammonium Lead Iodide. J. Phys. Chem. Lett. 2015, 6, 898-907.

(9) Miller, D. M.; Yablonovitch, E.; Kurtz, S. R. Strong Internal and External Luminescence as Solar Cells Approach the ShockleyQueisser Limit. IEEE J. Photovoltaics 2012, 2, 303-311.

(10) Xing, G.; Mathews, N.; Lim, S. S.; Yantara, N. N.; Liu, X.; Sabba, D.; Grätzel, M.; Mhaisalkar, S.; Sum, T. C. Low-Temperature Solution-Processed Wavelength-Tunable Perovskites for Lasing. Nat. Mater. 2014, 13, 476-480.

(11) Tan, Z.-K.; Moghaddam, R. S.; Lai, M. L.; Docampo, P.; Higler, R.; Deschler, F.; Price, M.; Sahanala, A.; Pazos, L. M.; Credgington, D.; et al. Bright Light-Emitting Diodes Based on Organometal Halide Perovskite. Nat. Nanotechnol. 2014, 9, 687-692.

(12) Li, G.; Tan, Z.-K.; Di, D.; Lai, M. L.; Jiang, L.; Lim, J. H-W.; Friend, R. H.; Greenham, N. C. Efficient Light-Emitting Diodes Based on Nanocrystalline Perovskite in a Dielectric Polymer Matrix. Nano Lett. 2015, 15, 2640-2644.

(13) Deschler, F.; Price, M.; Pathak, S.; Klintberg, L. E.; Jarausch, D.D.; Higler, R.; Hüttner, S.; Leijtens, T.; Stranks, S. D.; Snaith, H. J.; et al. High Photoluminescence Efficiency and Optically Pumped Lasing in Solution-Processed Mixed Halide Perovskite Semiconductors. J. Phys. Chem. Lett. 2014, 5, 1421-1426.

(14) Sutherland, B. R.; Hoogland, S.; Adachi, M. M.; Wong, C. T. O.; Sargent, E. H. Conformal Organohalide Perovskites Enable Lasing on Spherical Resonators. ACS Nano 2014, 8, 10947-10952.

(15) Stranks, S. D.; Burlakov, V. M.; Leitjens, T.; Ball, J. M.; Goriely, A.; Snaith, H. J. Recombination Kinetics in Organic-Inorganic Perovskites: Excitons, Free Charge, and Subgap States. Phys. Rev. Appl. 2014, 2, 034007.

(16) Hoke, E. T.; Slotcavage, D. J.; Dohner, E. R.; Bowring, A. R.; Karunadasa, H. I.; McGehee, M. D. Reversible Photo-Induced Trap Formation in Mixed Halide Hybrid Perovskites for Photovoltaics. Chem. Sci. 2015, 6, 613-617.

(17) Tian, Y.; Merdasa, A.; Peter, M.; Abdellah, M.; Zheng, K.; Ponseca, C. S., Jr.; Pullerits, T.; Yartsev, A.; Sundström, V.; Scheblykin, I. G. Giant Photoluminescence Blinking of Perovskite Nanocrystals Reveals Single-Trap Control of Luminescence. Nano Lett. 2015, 15, 1603-1608.

(18) Xiao, M.; Huang, F.; Huang, W.; Dkhissi, Y.; Zhu, Y.; Etheridge, J.; Gray-Weale, A.; Bach, U.; Cheng, Y.-B.; Spiccia, L. A Fast Deposition-Crystallization Procedure for Highly Efficient Lead Iodide Perovskite Thin-Film Solar Cells. Angew. Chem. 2014, 53, 9898-9903.

(19) Jeon, N. J.; Noh, J. H.; Kim, Y. C.; Yang, W. S.; Ryu, S.; Seok, S. I. Solvent Engineering for High-Performance Inorganic-Organic Hybrid Perovskite Solar Cells. Nat. Mater. 2014, 13, 897-903.

(20) Xing, G.; Mathews, N.; Sun, S.; Lim, S. S.; Lam, Y. M.; Grätzel, M.; Mhaisalkar, M.; Sum, T. C. Long-Range Balanced Electron and Hole-Transport Lengths in Organic-Inorganic $\mathrm{CH}_{3} \mathrm{NH}_{3} \mathrm{PbI}_{3}$. Science 2013, 342, 344-347.

(21) Sánchez, R. S.; González-Pedro, V.; Lee, J.-W.; Park, N.-G.; Kang, Y. S.; Mora-Sero, I.; Bisquert, J. Slow Dynamic Processes in Lead Halide Perovskite Solar Cells. Characteristic Times and Hysteresis. J. Phys. Chem. Lett. 2014, 5, 2357-2363.

(22) Gottesman, R.; Haltzi, E.; Gouda, L.; Tirosh, S.; Buhadana, Y.; Zaban, A. Extremely Slow Photoconductivity Response of $\mathrm{CH}_{3} \mathrm{NH}_{3} \mathrm{PbI}_{3}$ Perovskites Suggesting Structural Changes under Working Conditions. J. Phys. Chem. Lett. 2014, 5, 2662-2669.

(23) Tress, W.; Marinova, N.; Moehl, T.; Zakeeruddin, S. M.; Nazeeruddin, M. K.; Grätzel, M. Understanding the Rate-Dependent $\mathrm{J}-\mathrm{V}$ Hysteresis, Slow Time Component, and Aging in $\mathrm{CH}_{3} \mathrm{NH}_{3} \mathrm{PbI}_{3}$ Perovskite Solar Cells: The Role of a Compensated Electric Field. Energy Environ. Sci. 2014, 8, 995-1004. 
(24) Snaith, H. J.; Abate, A.; Ball, J. M.; Eperon, G. E.; Leijtens, T.; Noel, N. K.; Stranks, S. D.; Wang, J. T-W.; Wojciechowski, K.; Zhang, W. Anomalous Hysteresis in Perovskite Solar Cells. J. Phys. Chem. Lett. 2014, 5, 1511-1515.

(25) Yin, W.-J.; Shi, T.; Yan, Y. Unusual Defect Physics in $\mathrm{CH}_{3} \mathrm{NH}_{3} \mathrm{PbI}_{3}$ Perovskite Solar Cell Absorber. Appl. Phys. Lett. 2014, 104, 063903.

(26) Buin, A.; Pietsch, P.; Xu, J.; Voznyy, O.; Ip, A. H.; Comin, R.; Sargent, E. H. Materials Processing Routes to Trap-Free Halide Perovskites. Nano Lett. 2014, 14, 6281-6286.

(27) Shkrob, I. A.; Marin, T. W. Charge Trapping in Photovoltaically Active Perovskites and Related Halogen Plumbate Compounds. J. Phys. Chem. Lett. 2014, 5, 1066-1071.

(28) Noel, N. K.; Abate, A.; Stranks, S. D.; Parrott, E.; Burlakov, V.; Goriely, A.; Snaith, H. J. Enhanced Photoluminescence and Solar Cell Performance via Lewis Base Passivation of Organic-Inorganic Lead Halide Perovskites. ACS Nano 2014, 8, 9815-9821.

(29) You, J.; Yang, Y.; Hong, Z.; Song, T.-B.; Meng, L.; Liu, Y.; Jiang, C.; Zhou, H.; Chang, W.-H.; Li, G.; et al. Moisture Assisted Perovskite Film Growth for High Performance Solar Cells. Appl. Phys. Lett. 2014, 105, 183902.

(30) Pathak, S.; Sepe, A.; Sadhanala, A.; Deschler, F.; Haghighirad, A.; Sakai, N.; Goedel, K. C.; Stranks, S. D.; Noel, N.; Price, M.; et al. Atmospheric Influence upon Crystallization and Electronic Disorder and Its Impact on the Photophysical Properties of OrganicInorganic Perovskite Solar Cells. ACS Nano 2015, 9, 2311-2320.

(31) Abate, A.; Saliba, M.; Hollman, D. J.; Stranks, S. D.; Wojciechowski, K.; Avolio, R.; Grancini, G.; Petrozza, A.; Snaith, H. J. Suprammolecular Halogen Bond Passivation of Organic-Inorganic Halide Peovskite Solar Cells. Nano Lett. 2014, 14, 3247-3254.

(32) Cordero, S. R.; Carson, P. J.; Estabrook, R. A.; Strouse, G. F.; Buratto, S. K. Photo-Activated Luminescence of CdSe Quantum Dot Monolayers. J. Phys. Chem. B 2000, 104, 12137-12142.

(33) Osborne, M. A.; Lee, S. F. Quantum Dot Photoluminescence Activation and Decay: Dark, Bright, and Reversible Populations in ZnS-Capped CdSe Nanocrystals. ACS Nano 2011, 5, 8295-8304.

\section{NOTE ADDED AFTER ASAP PUBLICATION}

This Letter was published ASAP on May 27, 2015 with incorrect information for ref 17 . The corrected version was reposted on June 2, 2015. 